\title{
Acute Urinary Retention: Should We Call it a Manifestation of Appendicitis?
}

\author{
Sadaf Sheikh ${ }^{1}$, Umair Javed ${ }^{2}$ and Muhammad Akbar Baig ${ }^{2}$ \\ ${ }^{1}$ Department of Emergency Medicine, Sultan Qaboos University Hospital, Muscat, Oman \\ ${ }^{2}$ Department of Emergency Medicine, The Aga Khan University Hospital, Karachi, Pakistan
}

\begin{abstract}
Acute urinary retention (AUR) is a fairly common presentation in the elderly; but interesting to be noted in a healthy young individual as a manifestation of acute appendicitis. We present a case of a 32-year gentleman with decreased urine output with mild tenderness at the supra-pubic region; which was later on, shifted to the right iliac fossa. Computed tomography of the abdomen showed acute appendicitis. Emergency physicians are challenged to recognize the uncommon presentation of acute appendicitis and need to be reminded of this common complaint as a rare presentation of it. This case also stresses on the repeated abdominal examinations to seek diagnostic clarity.
\end{abstract}

Key Words: Appendicitis, Acute urinary retention, Repeat abdominal examination.

How to cite this article: Sheikh S, Javed U, Baig MA. Acute Urinary Retention: Should We Call it a Manifestation of Appendicitis?. J Coll Physicians Surg Pak 2021; 31(07):846-848.

\section{INTRODUCTION}

The classical presentation of acute appendicitis is well known: peri-umbilical pain radiating to right iliac fossa with nausea, vomiting and anorexia. Yet, this presentation is not always there to indicate the diagnosis. Less has been published regarding atypical presentation of acute appendicitis and one needs to think of alternative diagnosis in the setting of acute urinary retention (AUR). ${ }^{1,2}$ We, herein, present a case of a young male with no comorbidities, who presented in the emergency department with AUR as the initial presentation of acute appendicitis. With careful and repeated examinations and computed tomography, it was possible to arrive at the correct diagnosis of the condition.

\section{CASE REPORT}

A previously healthy 32-year male, presented to the Emergency Department with complain of inability to pass urine for the past 8 hours, associated with low abdominal pain. Lower abdominal pain was non-radiating, dull in character with no clear aggravating and relieving factors. There was no associated nausea and vomiting. He reported normal appetite and reported no history of fever. He had no prior urological history and denied any history of urethral discharge.

Correspondence to: Dr. Sadaf Sheikh, Department of Emergency Medicine, Sultan Qaboos University Hospital, Muscat, Oman

E-mail: sheikh.sadaf@gmail.com

Received: October 08, 2019; Revised: February 12, 2020; Accepted: March 02, 2020

DOI: https://doi.org/10.29271/jcpsp.2021.07.846
Sexual history was unremarkable. Past surgical and medical history was unremarkable. Moreover, there was no prior history of kidney stones or urethral stricture. Bowel habits were normal and patient denied any addiction.

On arrival, the patient was afebrile, had heart rate of 76 beats per minute, blood pressure of $126 / 72 \mathrm{mmHg}$, respiratory rate of 18 breaths/min and oxygen saturation on pulse oximeter of $99 \%$ on room air. General physical examination was unremarkable except for dry mucosa and skin. Abdominal examination revealed soft abdomen with mild tenderness in the lower abdomen. Bladder was palpable midway between symphysis pubis and umbilicus. Normal gut sounds were audible on auscultation. There was no rebound tenderness or costo-vertebral tenderness. Rest of the systemic examination was unremarkable. Genitourinary examination was also unremarkable.

Foley's catheterisation was done without any complication. Post-void residual volume of $400 \mathrm{ml}$ was obtained. Initial laboratory investigations are shown in Table 1. Urinalysis reported negative leucocyte esterase, nitrites and leukocytes with hemoglobin $1+$ and ketone $1+$ on dipstick testing.

Symptom reassessment performed after two hours revealed that lower abdominal pain did not settle. Abdominal examination after two hours revealed lower abdominal tenderness to be more marked in the right iliac fossa. Rovsing's sign, obturator sign and psoas sign were negative. Rebound tenderness was positive. Alvarado score was 5 points ( 1 for rebound tenderness, 1 for right iliac fossa tenderness, 2 for elevated leukocyte count and 1 for leukocyte left shift).

Focus assessment computed tomography reported dilated appendix of $10.5 \mathrm{~mm}$ with multiple high density foci within its 
lumen representing appendicoliths. Mild free fluid and peri-appendiceal inflammatory changes were present (Figures 1 and 2).

Patient was admitted in general surgery care and underwent uneventful laparoscopic appendectomy and was discharged home on first postoperative day.

Table l: Laboratory investigations at the time of presentation.

\begin{tabular}{|l|l|}
\hline Hemoglobin & $15.9 \mathrm{~g} / \mathrm{dl}$ \\
\hline Hematocrit & $46.1 \%$ \\
\hline Mean corpuscular volume & $82.5 \mathrm{fL}$ \\
\hline White blood cells & $14.1 \times 10^{9} / \mathrm{l}$ \\
\hline Neutrophils & $88.1 \times 10^{3}$ cells/ul \\
\hline Lymphocytes & $5.2 \times 10^{3} \mathrm{cells} / \mathrm{ul}$ \\
\hline Platelets & $265 \times 10^{3} / \mathrm{ul}$ \\
\hline Blood urea nitrogen & $9 \mathrm{mmol} / \mathrm{L}$ \\
\hline Creatinine & $1 \mathrm{mg} / \mathrm{dL}$ \\
\hline Sodium & $135 \mathrm{mEq} / \mathrm{L}$ \\
\hline Potassium & $3.3 \mathrm{mEq} / \mathrm{L}$ \\
\hline Chloride & $96 \mathrm{mEq} / \mathrm{L}$ \\
\hline Bicarbonate & $28.8 \mathrm{mg} / \mathrm{dL}$ \\
\hline Urine cultures & No growth \\
\hline
\end{tabular}

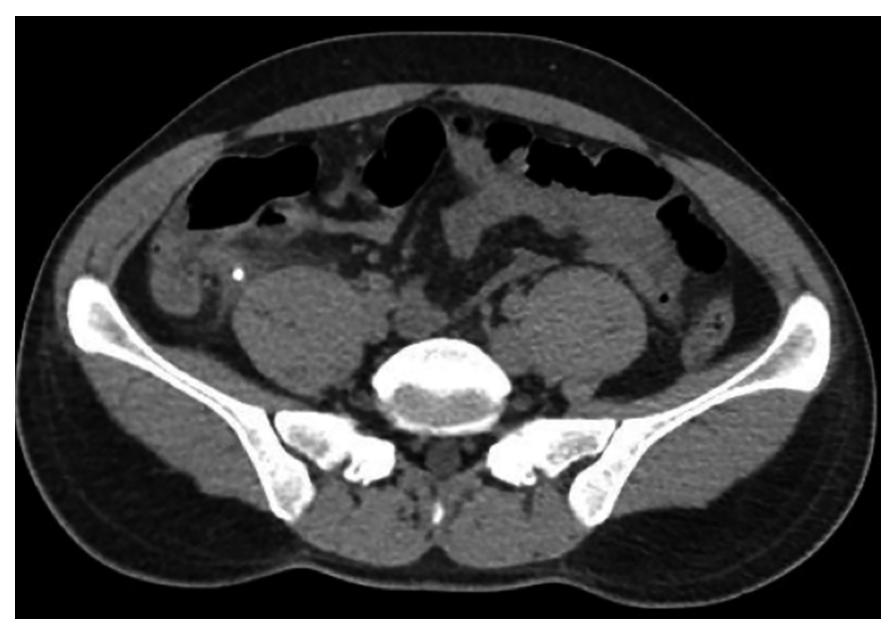

Figure 1: Axial view of computed tomography abdomen showing appendicolith (blackarrow).

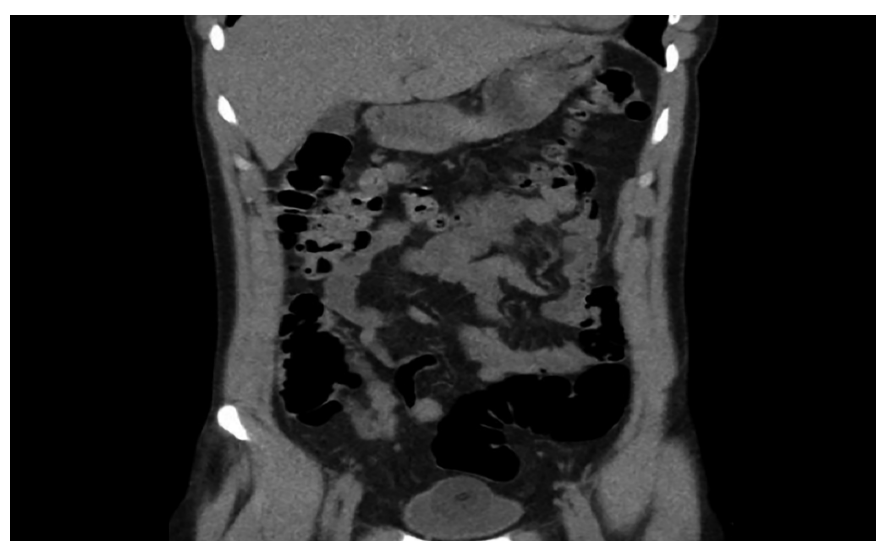

Figure 2: Coronal image of computed tomography abdomen showing peri-appendiceal inflammation (blackarrow).

\section{DISCUSSION}

Acute appendicitis is the high volume diagnosis in the Emergency Room. As emergency physicians, we do not always consider the mimicking conditions for acute appendicitis; more- over, it has a complex and atypical range of presentations leading to missed diagnosis. ${ }^{1}$

It is common to operate on ureteric stone with a preoperative diagnosis of appendicitis, but on the contrary, mistakes could happen in the case of urological manifestations of acute appendicitis.

This case report focuses on the variability in manifestations of acute appendicitis, notably AUR and microscopic hematuria. This variability likely originates from the location of appendix leading to diagnostic dilemmas. Appendicitis manifesting as AUR is a rarity, particularly in young patients. Urological manifestations of acute appendicitis which may otherwise point to the pathology of genito-urinary system, may include dysuria, urinary frequency, AUR, rectal pain or testicularpain. ${ }^{2}$

Dysuria is the result of irritation of urinary bladder in case of peri-appendiceal inflammation. In cases of pelvic appendix, it is not common to have abdominal rigidity misleading the examiner to think about bladder pathology. Patients complain that they have got full bladder but there are no complaints about passing urine. ${ }^{2}$ It is mainly seen when the appendix is behind the cecum, in the iliac fossa or deep in the pelvis. Retention of urine is due to the irritation of bladder sphincter, which is an uncommon phenomenon; yet, difficulty in urination is a common complaint. ${ }^{2}$

Differential diagnosis becomes relatively easier, if urine is examined well. While differentiating it from pyelitis, acute appendicitis reveals normal detailed report (DR) of urine with rigidity of abdominal muscles and fever. Tenderness at right erector-costal angle does present in the acute appendicitis due to $10^{\text {th }}$ dorsal spinal nerve which supplies the appendix. ${ }^{2}$ Literature has shown such rare presentations in acute appendicitis as gross hematuria, acute prostatitis and acute pyelonephritis. ${ }^{3,4}$ Such unusual manifestations of acute appendicitis should be considered in the differential diagnoses of AUR. ${ }^{5,6}$ In conclusion, this case highlights the need to keep AUR as a rare and atypical presentation of acute appendicitis in otherwise young and healthy males.

\section{PATIENT'S CONSENT:}

Verbal consent was obtained from the patient to publish the data concerning this case.

\section{CONFLICT OF INTEREST:}

The authors declared no conflict of interest.

\section{AUTHORS' CONTRIBUTION:}

SS, UJ, MAB: Contributed in drafting and editing of the work.

\section{REFERENCES}

1. Munson RJ, Fontanarosa PB, Gerson L: Acute appendicitis in elderly: Clinical features of early and delayed diagnoses. Ann Emerg Med 1992; 21:636-7.

2. Zachary Cope V. Genito-Urinary Symptoms in Acute Appendicitis. First Published June 1, 1922 Meeting Report. 
http://doi.org/10.1177/003591572201501901

3. Fontanarosa PB, Roush WR: Acute urinary retention. Emerg Med Clin North Am 1988; 6(3):419-37.

4. Jones WG, Barie PS. Urological manifestations of acute appendicitis. J Urol 1988; 139(6):1325-8.

5. Liu CC, Yen DH, Lu CL, Chern $\mathrm{CH}$, Lee $\mathrm{CH}$. Acute urinary retention in the elderly: an unusual presentation of appendicitis with a high perforation risk. Gerontology 2002; 48(6):387-91.

6. Simson N, Stonier T, Coscione A, Qteishat A. A rare urological presentation of appendicitis. BMJ Case Reports 2017; 2017:bcr-2017-220546. 